\title{
Código de Ética
}

La revista Ecosistemas y Recursos Agropecuarios se compromete a cumplir y respetar los principios de transparencia y buenas prácticas en las publicaciones académicas del Comité de Ética en la Publicación (COPE). El presente código de ética hace referencia a la honestidad de los Autores, del Comité Editorial y los Revisores. En este contexto, la revista Ecosistemas y Recursos Agropecuarios exige: a) A los autores, originalidad y autenticidad en sus manuscritos; b) A los editores y los revisores, transparencia y objetividad en el arbitraje; y c) A todos los involucrados, no incurrir en fraudes científicos.

\section{Comité Editorial}

1.- Fomentar una política de transparencia en la recepción, revisión, selección y publicación de los manuscritos recibidos.

2.- Dar seguimiento transparente de los procesos establecidos en la edición de la Revista.

3.- Respetar la libertad de expresión y fomentar el respeto al derecho de autor.

4.- No permitir conflicto de intereses entre Autores y los Editores en ningún punto del proceso de arbitraje.

\section{Editores}

1.- Mejorar de forma continua los estándares de calidad en la selección de los manuscritos, de los revisores y del proceso de revisión; considerando siempre la relevancia científica del manuscrito, originalidad, claridad y pertinencia.

2.- La decisión del editor de aceptar o rechazar un manuscrito para su publicación debe basarse en la relevancia científica y originalidad.

3.- Proteger la confidencialidad del proceso de arbitraje, cuidando el anonimato de árbitros y autores.

4.- Realizar el proceso de arbitraje y dictamen de los manuscritos y su contenido sin distinción de raza, género, creencias religiosas, origen étnico, nacionalidad, orientación sexual o filosofía política de los autores.

\section{Autores}

1.- Redactar un manuscrito sin manipulación de datos y sin uso de autoría ficticia o plagio. Considerando como autor(es) a quien(es) participaron en la investigación.

2.- Enviar manuscritos originales e inéditos, citando las fuentes originales que fundamentan y sustentan sus resultados, para reconocer la contribución científica de otros autores.

3.- Garantizar que sus trabajos no han sido publicados o que no están siendo considerados en otra publicación. Se considera un trabajo como previamente publicado cuando ocurra cualquiera de las siguientes situaciones: 1) Cuando el texto completo haya sido publicado, 2) Cuando fragmentos extensos de materiales previamente publicados formen parte del manuscrito enviado a la Revista y no existan cambios sustanciales en las aportaciones del mismo, y 3) Cuando el trabajo sometido a la revista esté contenido en memorias publicadas in extenso. Es necesario enfatizar que la revista tiene la facultad de rechazar un artículo cuando detecte plagio o auto plagio, en cualquier punto del proceso de arbitraje o retirarlo en caso de que haya sido publicado. 


\section{CÓDIGO DE ÉTICA}

4.- En el caso del uso de animales de experimentación se solicita a los autores apegarse a los lineamientos ARRIVE (Animal Research: Reporting In Vivo Experiments), desarrollados por NC3Rs. Mientras que, en el caso de manipulación de flora y fauna silvestre, así como en áreas naturales protegidas es necesario contar con los permisos de las autoridades correspondientes

5.- Atender con precisión los comentarios, correcciones y sugerencias realizadas por los árbitros y el editor. En caso de no estar de acuerdo con las observaciones, es necesario fundamentar en detalle las razones por las que no se aceptan las observaciones.

6.- Para la publicación de los manuscritos, los autores deben seguir de manera puntual los lineamientos descritos en la Guía para Autores, disponible en el sitio web de la revista, además de respetar los tiempos asignados en el proceso de revisión.

7.- Declarar posibles conflictos de interés relacionados con el tema que se aborda en el manuscrito. Además de disponer de la autorización de uso de todo material protegido que haya sido utilizado en el manuscrito a publicar. La información contenida en cada uno de los artículos es responsabilidad de los autores.

8.- El o los autores principales deben asegurarse de que todos los co-autores han revisado y aprobado la versión final del manuscrito.

9.- Si un autor está convencido de que se ha tomado una decisión incorrecta con respecto a su manuscrito, Ecosistemas y Recursos Agropecuarios le permite presentar una única apelación. La apelación debe enviarse con información detallada sobre las razones por las cuales la decisión inicial estuvo equivocada. La situación será atendida por el Comité Editorial de la revista. En algunos casos, el proceso podría involucrar una nueva revisión del manuscrito, la nueva decisión se considera definitiva.

\section{Revisores}

1.- Como expertos en la materia tienen el compromiso de revisar y hacer observaciones al manuscrito de manera objetiva e imparcial, con comentarios respetuosos y argumentos precisos que contribuyan a la mejora del manuscrito; así como realizar el llenado del formato de dictamen en el sistema OJS de la revista dentro de los plazos establecidos.

2.- Tienen la obligación de asegurar la confidencialidad del artículo revisado y de no hacer uso de la información antes de que sea publicada.

3.- Los revisores se comprometen a notificar sobre cualquier conducta no ética por parte de los autores y señalar toda la información que pueda ser motivo para rechazar el manuscrito.

4.- Los revisores no deben evaluar los manuscritos en los que tienen conflictos de intereses. 